\title{
Sobre o tempo que passou: a imersão na paisagem cibernética e o surgimento de novas temporalidades e formas de perceber o tempo
}

\author{
Mauro Meirelles (1), Cintia Inês Boll (2) \\ (1) Licenciado em Ciências Sociais (UFRGS), Mestre em Educação (PPGEDU/ \\ UFRGS) e Doutorando em Antropologia Social (PPGAS/UFRGS) \\ e-mail:mauro-meirelles@hotmail.com \\ (2) Licenciada em Pedagogia (UFRGS), Mestre em Educação (PPGEDU/UFRGS), \\ Doutoranda em Educação (PPGEDU/UFRGS) e professora assistente da UnB \\ cintiainesboll@yahoo.com.br
}

\begin{abstract}
RESUMO
O presente artigo versa sobre a forma como o tempo é percebido a partir do uso quotidiano das novas tecnologias da informação e comunicação, em especial o computador. Para este fim, nos utilizamos de bases de dados construída a partir de pesquisa realizada em 2005 e de dados oriundos da experiência de cerca de sete anos com a modalidade de ensino a distância, ora como professor, ora como aluno, ora como tutor. Neste sentido, os resultados apontam que cada vez mais cresce o acesso a diferentes tecnologias que acabam por transformar o quotidiano das pessoas, alterando, assim, significativamente a forma como, estas, se relacionam como o tempo a partir de sua imersão no ciberespaço ou, naquilo, que denominamos de paisagem cibernética.
\end{abstract}

Palavras-chave: ciberespaço, percepção do tempo, educação a distância, novas tecnologias 
Então me abraça forte/E diz mais uma vez

Que já estamos/Distantes de tudo Temos nosso próprio tempo (3x) ...

Renato Russo

(Tempo Perdido, 1986)

Tempo, tempo, tempo mano velho Tempo, tempo, tempo mano velho Vai, vai, vai, vai, vai, vai

Tempo amigo seja legal Conto contigo pela madrugada Só me derrube no final

Pato Fu

(Sobre o tempo, 1995)

\section{Introdução: As culturas e o tempo}

Muitos são os trabalhos que se ocupam da noção de cultura como uma lente a partir da qual nós (educadores e antropólogos) realizamos uma leitura do mundo e buscamos contextualizar determinados fenômenos ou eventos no interior de determinado grupo social ou comunidade. Contudo, pouco tem-se avançado no sentido de se construir um conceito unívoco de cultura de modo que, como bem ilustra KUPER (2002), diversas são as formas como nós, antropólogos e educadores, nos relacionamos teoricamente com ela. Neste sentido, importa esclarecer que, neste artigo, nos utilizaremos o termo/palavra "cultura" enquanto um léxico substantivo dotado de um profundo caráter polissêmico e plural devendo-se, sempre, considera-la em função de suas especificidades compósitas, as quais, condicionam historicamente nosso entendimento do mundo, de nós mesmos, de nossa cultura e de nosso duplo, o outro.

Isto posto, tem-se ainda que a forma como as mais diferentes culturas percebem o tempo e com ele se relacionam é diversa. O tempo cronológico, da máquina, do relógio, do calendário, assume, assim, um caráter único em cada cultura em função de uma meta-agenda histórico-cultural que valora/desvalora determinados usos e vivências do tempo. Exemplo disto é o modo como os calendários judaico, lunar e gregoriano assumem limites temporais diversos em função de diferentes referentes histórico-culturais tidos como elemento fundante de toda uma cosmogonia que dele deriva. O tempo objetivo é, portanto, o tempo-máquina, o tempo do relógio, é a hora de sessenta minutos, é, enfim, a hora de 3600 segundos. 
Todavia, apesar de passível de uma medição objetiva, esse tempo, a hora de sessenta minutos, pode ser percebida de forma diversa por diferentes pessoas que compartilham um mesmo quinhão de 3600 segundos. Disto deriva que, uma mesma hora pode ser mais longa para aquele que estuda matemática ou química e que vê os ponteiros do relógio arrastarem-se rumo a hora fechada do que, a hora vivida por aquele que lê sua revista favorita ou está na praia e vê os ponteiros do relógio correrem de forma frenética rumo ao sexagésimo minuto, parecendo-nos que, essa hora teve muito menos que sessenta minutos. Curta ou longa, a hora continua a ser do mesmo tamanho e composta por 60 ciclos de 60 segundos, contudo, a forma como esse tempo é percebido é diversa e se relaciona a forma como nós o percebemos e nos relacionamos com ele. E assim, sem dantes nos firmamos em definições conceituais precisas, servimo-nos desses exemplos quotidianos para pensarmos o tempo e a forma como, nós, os modernos, para usar a terminologia empregada por LATOUR (2000), nos relacionamos com ele e o percebemos em função de diferentes referenciais semânticos que dotam esse tempo de uma temporalidade diversa que deixa de ser o tempo-máquina e torna-se o tempo vivido.

Agora, se formos mais adiante, e pensarmos em termos lexicais, o tempo assume no interior da linguagem, segundo RICOUER (1975), uma diversidade gramatical muito grande que se relaciona ao que poderíamos chamar de uma sintaxe do tempo, ou seja, a forma como esse tempo é utilizado, substantivado, subjetivado por aquele que o toma para si. Neste sentido, na esteira do exposto por esse mesmo autor, é consenso entre um bom número de autores, entre eles LARRE (1975), PANIKKAR (1975), BAUMER (1975), KAGAME (1975), NEHER (1975), PATTARO (1975) e GOUREVITCH (1975) que o tempo máquina é antes de mais nada, um tempo da linguagem, um tempo que se insere naquilo que é vivido no interior de uma determinada cultura, essa última, entendida, também, como plural e diversa.

O tempo vivido, o tempo em sala de aula, o tempo que vivemos é o "nosso tempo" e assume-se, quase sempre, como diacrônico e fora do claustro do tempo-máquina. É um tempo com duração perceptiva diversa, é o tempo do sujeito. É o tempo que se sobrepõe no quotidiano da menina-mãe que teve sua infância encerrada precocemente, que estuda, que cuida do filho e da casa, é o tempo do jovem que trabalha para ajudar em casa, que estuda, que faz cursos a distância, que assiste a aula no computador enquanto ouve música, conversa no msn e olha seus e-mails. Tudo isso, como diria Arnaldo Antunes, ao mesmo tempo, agora. Isto posto, tem-se que o tempo vivido pelo indivíduo só é inteligível dentro da cultura e da 
história que lhe deu origem, da "sua história", da "história da sua comunidade" e a forma como este indivíduo se relaciona com o espaço em que vive e com o tempo, algo que, na antropologia, chamamos de uma etnografia da duração (ECKERT \& ROCHA, 2000).

É o tempo dos moradores da Ilha dos Marinheiros estudados por DEVOS (2007) em sua tese de doutorado, esse tempo, diverso daquele dos habitues da Praça da Alfândega e da Rua dos Andradas, estudados por CUNNEGATO (2009) em sua dissertação de mestrado. É um tempo que se configura na história, na linguagem e na forma como ele é vivido e dotado de sentido por aqueles que lhe consomem vorazmente os segundos, os minutos, as horas. Mas, para além desse tempo vivido há, também, o tempo da narrativa, o tempo do discurso, o tempo da palavra, o tempo das coisas ditas. E, é RICOUER novamente que nos lembra que várias são as culturas que

[...] Têm suas concepções implícitas ou explícitas de tempo ligadas à um surgimento de Palavra - ou de Escritura - que cria, em benefício de um evento de discurso fundador, o conjunto das experiências, dos comportamentos e das interpretações que, por sua vez, constituem o vivido singular característico dessa cultura (RICOUER: 1975, p. 22).

Exemplos dessa vivência diversa é a forma como o tempo cristão é narrado no velho e no novo testamento, ou ainda, como o tempo e a história são percebidos de forma diferenciada dentro da cultura judaica e muçulmana como bem mostram NEHER (1975) e PATTARO (1975). E, mais recentemente, ainda ancorados em RICOUER (1994) diríamos que o sentido do tempo se dá a partir da produção de diferentes circuitos que têm na intriga seu enredo, seu elemento aglutinador. Neste sentido, é ilustrativo que parábolas cristãs só façam sentido dentre aqueles que possuem receptáculos culturais capazes de decodificá-los enquanto que, outras, caras a cultura oriental, só tenham sentido dentro de culturas milenares como a chinesa e/ou japonesa onde surgiram.

Desta constatação, depreende-se um duplo movimento, um no sentido daquilo que sabemos sobre o mundo, daquilo que nos é informado, que nos pré-figura e configura (mímese I) e, outro, no sentido daquilo que percebemos com produto final, como aquilo que se observa, que se conta, que se quer deixar ver, que se vive (mímese III). Todavia, nos falta o enredo, a narrativa que dá sentido aquilo que nos é contado, a intriga (mímese II). No tempomáquina, aquele do vai-e-vêm do pêndulo do relógio temos a hora medida em intervalos de sessenta minutos (mímese I). No tempo subjetivo, vivido em horas curtas e/ou longas, ou 
ainda, de forma sobreposta na menina-mãe que estuda e cuida da casa e do filho, ou do jovem que trabalha e estuda a distância, que acessa seus e-mails, ouve música e conversa no msn enquanto assiste uma aula via EAD temos o produto final dessa interação do indivíduo com a linguagem (mímese III). E, com isto, tem-se que, fora desse circuito e da cultura que lhe dá sentido (mímese II), essa vivência do tempo deixa de ter sentido e torna-se um significante vazio.

Algo semelhante ao que PATTARO (1975) pondera quando se ocupa do tempo cristão e afirma categoricamente que tais circuitos da mímese só fazem sentido na cristologia na medida em que, no seu interior, articula-se não só a interpretação do tempo cristico, mas também, outros tempos. No interior da cultura cristã "o tempo não é só interpretado, mas também, significado pelo rito" (RICOEUR, 1975, p. 25). Neste sentido, é o tempo de Cristo, do antes e do depois, de sua estadia na terra, que ordena todos os outros tempos, uma vez que

[...] O Novo Testamento valoriza inteiramente o tempo, ao contrário do helenismo presumido, sua maneira de articular os "tempos privilegiados" dentro do tempo o opõe ao judaísmo. A singularidade de sua concepção tem, pois, duas faces. É o tempo de Cristo que ainda determina a ordenação de todos os tempos. Sua "hora" (João), seu Kairos (Sinóticos e Epístolas), é o evento-chave da Morte e Ressurreição. E sua escolha é a de Deus. Todos os outros Kairoi são marcados por aquele, adiante como atrás, tanto o tempo presente da igreja, quanto o dia do Juízo. A história bíblica é a cadeia sucessiva desses Kairoi dirigidos para Cristo e por Cristo. A tensão dessa história se deve ao fato de que o Kairos central passou, mas sua manifestação inteira está para suceder. (RICOUER: 1975, p. 24)

Dito de outra maneira, é o próprio Cristo que faz do seu tempo a medida determinante ao estabelecer uma tensão entre o "já" e o "ainda não", tensão esta, que impede que o futuro se transforme em uma simples memória de evento-chave. É assim que, o Cristo, no interior da história cristã realiza todo o passado e antecipa o futuro, através de marcações bem claras entre aquilo que está antes (A.C.) e depois (D.C.) da vinda do cordeiro de Deus à Terra. E neste sentido, enganam-se aqueles que consideram que a utilização da vinda de um profeta ou salvador, este, tido como evento-chave de toda uma cronologia/calendário/forma de contar o tempo é uma exclusividade dos cristãos, uma vez que, em outras culturas, outros são os marcadores temporais que servem como forma de ordenar o tempo, como por exemplo, o ciclo da lua entre os índios norte-americanos, o período de cheia das águas entre os índios amazônicos e outras populações ribeirinhas, etc.

Outrossim, em tempos de uma modernidade-mundo em que nos tornamos senhores das máquinas, e também, seus escravos, assumimos uma nova forma de perceber o tempo e, Sobre o tempo que passou: a imersão na paisagem cibernética e o surgimento de novas temporalidades... 
não saímos de casa sem antes olharmos nossos e-mails e darmos uma olhada em algum portal de notícia, mas, fundamentalmente, e isso não podemos esquecer de levar: o nosso celular. E, novamente voltamos ao A.C. e D.C., ao antes e ao depois do ciberespaço, onde nossa existência é revista e quotizada em pares binários e sequências numéricas únicas, a partir daquilo que GIBSON (1984) num de seus clássicos da ficção científica nomeia e define como ciberespaço.

\section{Inaugurando um novo tempo: as novas tecnologias da informação e a nossa imersão na paisagem cibernética}

De um maneira geral temos que o que hoje denominamos de novas tecnologias da informação e comunicação através de seu acrônimo NTICs nada mais é que um modo de nos referirmos a um conjunto de ferramentas e medias que a partir dos anos de 1960 passaram a fazer parte do quotidiano escolar e de políticas de governo relacionadas a formação de professores em serviço e/ou da alfabetização e formação de pessoas que, doutra forma, não teriam como chegar até uma escola regular. Exemplos recentes deste tipo de iniciativa são o TV Escola, o Telecurso 2000 e o PROINFO.

Todavia, não nos ocuparemos aqui de todos os suportes hoje utilizados, os quais vão desde as antigas ondas de rádio até o uso de modernos satélites de comunicação e antenas de captação e transmissão de sinal para os mais longínquos lugares de nosso país. Nesse entremeio, entre o velho transistor e o moderno componente integrado do satélite temos a televisão, os CDs, os DVDs interativos e o computador. E, é com a forma como essas novas tecnologias, em especial, o computador foram capazes de alterar nossa relação com o tempo e com o espaço que nos ocuparemos daqui para diante.

Neste sentido, iniciaremos o trabalho trazendo alguns dados de pesquisa de campo realizada no ano de 2005 entre alunos da rede pública e privada do RS para, em seguida, a partir do trabalho que desenvolvi como tutor de sede e, também desenvolvedor, por cerca de um ano junto ao curso de Pedagogia a Distância da UFRGS, de cerca de dois anos de 
desenvolvimento de uma plataforma $\mathrm{PPH}^{1}$ com vistas ao de acompanhamento do estágio docente das licenciaturas junto com a Prof. Cíntia Inês Boll², de quase dois anos da criação do LAVIECS $^{3}$ e de minha atuação junto a outras iniciativas de diversos cursos desta e de outras universidades, pensar a forma como essa relação foi sendo transformada ao longo dos últimos cinco a sete anos, período em que estive mais efetivamente envolvido no trabalho com esse suporte.

Outrossim, sem me deter em um cronologia exata dos eventos nem em retomar tudo o que se falou ou pensou dos diversos suportes que hoje se fazem presente na educação, me ocuparei, pontualmente, nas mudanças que sua incorporação implicou tanto para aqueles que se utilizam desse suporte para produção de suas aulas como aqueles que delas fazem uso para seu aprendizado. Em princípio, podemos pensar essas mudanças como tributárias a forma como nos relacionamos com esses outros que emergem a partir do uso do Rádio, da Televisão e da Internet como suporte para o ensino e educação a distância: o outro co-presente mas nãovisível; o outro visível mas nem sempre co-presente; e, o outro digital. Esse último, avatar e extensão de nosso eu, representação idealizada de nós mesmos na nuvem de zeros e uns que nós dá vida e forma ao maravilhoso mundo que surge a partir do clássico livro de GIBSON (1984).

\section{O uso das novas tecnologias da informação}

1 O PPH, ou Planejamento Pedagógico Hipermididático, é uma plataforma de acompanhamento de estágio destinada ao acompanhamento e construção do planejamento pedagógico que permite ao aluno, através do uso do computador, agregar diversas mídias ao seu plano de ensino, tais como: imagens, texto, vídeo, áudio, pdfs, etc. Nesse sentido, também cabe destacar que seu desenvolvimento só foi possível graças ao financiamento e apoio da Secretária de Educação a Distância da UFRGS que nos forneceu parte dos recursos humanos e tecnológicos para o desenvolvimento desse projeto.

${ }^{2}$ Atualmente, professora da Faculdade de Educação da Universidade Federal de Brasília (UnB).

3 O LAVIECS, ou Laboratório Virtual e Interativo de Ensino de Ciências Sociais, é uma iniciativa conjunta de professores da UFRGS e outros de outras instituições, de técnicos administrativos e alunos do curso de graduação em Ciências Sociais da UFRGS, e outros, do Programa de Pós-Graduação em Antropologia (PPGAS/ UFRGS), mas também, Sociologia (PPGS/UFRGS), a saber: Luiza Helena Pereira (IFCH/UFRGS), Mauro Meirelles (PPGAS/UFRGS), Graziele Ramos Schweig (PSICO/UFRGS), Leandro Raizer (PPGS/UFRGS), Thiago Ingrassia Pereira (IPA/Metodista), Jade dal Bó (IFCH/UFRGS) e Jonathan Henriques do Amaral (IFCH/ UFRGS). E neste sentido, têm servido como ponto de partida para a realização de pesquisas e o desenvolvimento de materiais digitais da UFRGS destinados a diversas disciplinas do curso de Ciências Sociais, assim como, outros, destinados a professores e alunos da rede pública de ensino. Mas, também, como repositório digital de textos que são acessados por pesquisadores e professores de todo o Brasil.

Sobre o tempo que passou: a imersão na paisagem cibernética e o surgimento de novas temporalidades... 
Antes de falarmos dos condicionantes históricos da sociedade brasileira e de suas implicações nas formas de conceber e perceber a realidade é preciso que exploremos um pouco a forma como chegamos até aqui. Para isto é interessante que tenhamos claro os interesses que cercam o uso de computadores, sejam estes, individuais ou coletivos. Neste sentido, também importa compreender a lógica sobre a qual se deu seu desenvolvimento e as implicações de sua utilização na vida quotidiana de milhares de pessoas ao redor do mundo. Grosso modo, iniciamos o presente item com um breve panorama da forma como se dá o acesso e uso de computadores ao redor do globo terrestre, para isto nos utilizaremos de dados disponibilizados pela Universidade de Harvard e por diversas agências de pesquisa especializadas em Internet, os quais já sistematizei em outro lugar (MEIRELLES, 2003).

Outrossim, como destacado pelo NATIONAL RESEARCH COUNCIL (1999), por BIANCHETTI (2001), e também presente como pano de fundo nas obras de CASTELLS (1999, 2003) e SILVEIRA (2001), as tecnologias ocupam cada vez mais um lugar de destaque em nosso cotidiano de modo que, para esses autores, dentre as diversas tecnologias existentes, as que apresentam maior potencial agregador são aquelas baseadas no suporte informático. Diante desta constatação, tanto a telefonia como as telecomunicações em geral têm buscado nesta ferramenta o devido suporte, migrando em larga escala - através de investimentos vultosos em tecnologia - do suporte analógico para o digital. Já no caso da educação temos o curso de Pedagogia a Distância da UFRGS que, notadamente, inaugura uma nova era no seio da universidade pública ao ser, no Brasil, o primeiro curso de graduação oferecido totalmente na modalidade a distância.

Observa-se também que, outros meios, como a televisão, o rádio e o jornal tradicionais meios de comunicação com distribuição não digital - estão agora, investindo neste suporte, e são disponibilizados em versões digitais. Outro exemplo disto são os celulares que cada vez mais aproximam suas interfaces gráficas e suas aplicações daquelas presentes em nossos computadores. Hoje já é possível enviar sons e imagens diretamente de aparelhos celulares, assim como navegar na Internet e baixar jogos e músicas no aparelho - algo impensável até alguns anos atrás, quando escrevi minha dissertação de mestrado, aos proprietários de aparelhos celulares no Brasil.

Assim, na convergência destas tecnologias para o suporte informático, o aspecto que mais se destaca, reside nos requisitos cognitivos e atitudinais exigidos tanto de trabalhadores 
como de profissionais egressos de universidades (NATIONAL RESEARCH COUNCIL, 1999), quanto de pessoas comuns (SILVEIRA, 2001; CASTELLS, 1999, 2003). Pois, nas palavras de BIANCHETTI (2001, p. 34)

\begin{abstract}
Processou-se, em decorrência dessa junção, uma transformação radical na forma e conteúdo do trabalho. A atuação passa a não ser mais "fatiada" entre pessoas e setores, conforme ocorria na atuação baseada no predomínio das regras da Gerência Científica. Além disso, deixa de ser sobre a matéria, como ocorreu em revoluções tecnológicas anteriores, e migra para o simbólico, exigindo uma outra/maior capacidade de abstração. A nova forma de executar e gerenciar o trabalho pressupõe um trabalhador capaz de assumir todas as fases do processo de produção.
\end{abstract}

Isso faz com que os trabalhadores - e não só estes - busquem novos conhecimentos com vistas a acompanhar a dinâmica das transformações tecnológicas que povoam o nosso quotidiano. Caso este, muito bem ilustrado por diversos trabalhos de conclusão do curso de Tutoria em Educação a Distância, do qual este, também, faz parte e que, em seu conjunto destacam um grande número de mudanças atitudinais e cognitivas que se fizeram necessárias tanto ao público discente como docente com vistas a implementação de uma proposta pedagógica diferenciada e inovadora baseada totalmente no suporte informático e no desenvolvimento de um trabalho conjunto que envolveu, inclusive, os tutores que trabalhavam junto a cada uma das interdisciplinas do curso.

E, deste modo, é com certa tranqüilidade, que afirmamos que a única certeza que temos é aquela antecipada por MCLUHAN (1969) em seu livro "Os meios de comunicação como extensões do homem" onde este coloca que a mudança teria se tornado a única constante na vida das pessoas. Isto exige, por sua vez, novas estratégias de desenvolvimento e adaptação por parte de todos os setores da sociedade para o convívio com o que CASTELLS (1999) denomina de "A Revolução das Novas Tecnologias da Informação". Contudo, esta dita revolução, só foi possível após o advento do computador pessoal (PC) e da Internet (World Wide Web), de modo que, sua evolução permitiu o desenvolvimento de rotinas e procedimentos até então impensáveis.

Desta feita e diante da crescente virtualização dos sistemas econômicos e das matrizes produtivas por meio da flexibilização das relações de trabalho, da onipresença de grandes corporações em lugares eqüidistantes do globo através de oficinas de trabalho descentralizadas e de parques produtivos dispersos geograficamente, é correto afirmar, como exposto por BIANCHETTI (2001), que o domínio da tecnologia digital sobre a analógica é 
inevitável. Uma vez que, a primeira é o suporte desta nova realidade que se descortina diante de nós. E que, é em seu âmago que conjuga-se o progresso científico e tecnológico e as opções políticas assumidas por seus governos ao longo da história (LATOUR, 2000; BIANCHETTI, 2001).

Com isto, as tecnologias digitais trazem sob seu escopo uma revolução permanente tanto no que tange ao mundo do trabalho como quanto no que se refere a proposição de novas abordagens pedagógicas, onde, categorias como tempo e espaço, assumem, novos significados. Surge uma nova temporalidade e espacialidade sob a égide das tecnologias digitais de interação e comunicação (TIRADO \& GÁLVEZ, 2002; BIANCHETTI, 2001). E, apesar de perspectivas diferenciadas tanto LEVY (1997) quanto SILVEIRA (2001) e CASTELLS $(1999 ; 2003)$ convergem em suas análises para o fato que estas tecnologias estão cada vez mais presentes em nosso quotidiano, impondo às pessoas, novos ritmos de interagir e pensar a realidade, ao mesmo tempo em que, ampliam as capacidades humanas e a forma de se utilizar e gerenciar a informação. O homem se hibridiza com a máquina, ampliando suas capacidades e possibilidades de interação no mundo real e virtual.

Já no que se refere, especificamente, ao acesso a internet temos que, em pesquisa realizada em 2005 constatou-se que grande parte dos alunos do ensino médio de Porto Alegre que, hoje, provavelmente estão na universidade, conseguiam ter contato com um computador, preferencialmente, no próprio domicílio em que residiam, mas também, na casa de amigos e na própria escola onde estudavam, de modo que, como já escrevi em outro lugar (MEIRELLES, 2005) o fato destes terem acesso a um computador resulta que em mais de $80 \%$ dos casos, estes, também, teriam acesso à Internet ${ }^{4}$. Se, então, até o presente momento, sabemos do acesso que estes possuem à um computador e a internet, cabe daqui para diante, explorar as imbricações desse novo sujeito-cibernético-protético que tem sobre si uma dupla história, uma de escolhas e opções feitas ao longo de sua vida, e outra, que se relaciona às interações, às traduções e às necessidades desse homem moderno com relação ao mundo objetivo e às exigências de uma cidadania plena do "e-mundo" das novas tecnologias da informação e comunicação, sobretudo, àquelas baseadas no suporte informático (SORJ, 1999).

\footnotetext{
${ }^{4}$ Isto posto, temos que há um maior grau de associação no tocante ao acesso a partir de suas residências $(\mathrm{x} 2=$ 52.102 e $p=0.000)$ e da casa de seus amigos $(x 2=29.639$ e $p=0.000)$, enquanto que, o acesso proveniente de outros locais não apresenta um grau de associação tão alto como os anteriores.
}

Sobre o tempo que passou: a imersão na paisagem cibernética e o surgimento de novas temporalidades... 
Ainda neste sentido, no que se refere a esse ponto, neste levantamento realizado em 2005 também constatou-se que, comparativamente, somente o acesso a diferentes softwares não bastam para que os usuários tenham o domínio de suas funções, uma vez que, os níveis mais altos de conhecimento estão entre aqueles que têm um computador com ou sem acesso a internet em sua residência ${ }^{5}$. Algo que foi igualmente observado em coleta de dados realizada no primeiro semestre do curso de Pedagogia a Distância da UFRGS, a qual, deixou evidente que o mero acesso ao suporte informático através da criação de pólos regionais não era suficiente de modo que, houve a necessidade de se pensar em oficinas e treinamentos que tinham por objetivo capacitar alguns tutores e alunos do pólo na utilização de determinados softwares que eram/seriam utilizados nas interdisciplinas de modo que, estes, servissem como multiplicadores. Da mesma forma, quando testada a mesma relação proposta - de que existe uma relação causal entre o local de acesso, sua conectividade e os níveis de conhecimentos que os usuários detêm com relação à determinados aplicativos - em outros lugares além de sua residência, podemos observar que, não houveram diferenças significativas na relação proposta, uma vez que, as comparações apresentadas a seguir confirmam a hipótese de que a conectividade à Internet se mostra como um fator determinante no aumento gradual dos níveis de conhecimentos dos usuários, independentemente do local de acesso ${ }^{6}$.

Ainda nesta direção, quando considerado o acesso à Internet como fator potencializador do desenvolvimento de conhecimentos relacionados ao uso do suporte informático, temos que, esta, mostra-se como um fator catalizador na medida em que, aqueles que estão conectados apresentam maiores níveis de conhecimentos relacionados à diferentes aplicações informáticas. Presentemente, observa-se que, aqueles que têm acesso quotidiano a computadores com Internet em sua casa, na casa de amigos ou na escola, são os que mais se utilizam e têm acesso aos dois browsers de navegação Internet Explorer e o Netscape.

No que diz respeito respeito ao uso de Programas de Mídia temos que o computador, também assume, cada vez mais, o papel de outros eletrodomésticos como os aparelhos de som

\footnotetext{
${ }^{5}$ De modo que, aqueles que têm um computador em seu domicílio têm duas vezes mais chances de usar todas as possibilidades oferecidas por uma aplicação informática na medida em que, dado o contato contínuo e o fácil acesso, aprofundam e desenvolvem muito mais rapidamente suas potencialidades com relação a esta.

6 Neste sentido, o teste qui-quadrado mostra que o acesso a um computador no domicílio ( $\mathrm{x} 2=68.541 \mathrm{e} \mathrm{p}=$ $0.000)$, na casa de amigos $(x 2=24.202$ e $\mathrm{p}=0.000)$, e, em cibercafés $(\mathrm{x} 2=13.355$ e $\mathrm{p}=0.004)$ está diretamente associado ao nível de conhecimento do usuário. Ao mesmo tempo em que, os dados também mostram haver uma certa associação entre os diferentes níveis de conhecimento que estes detêm e o acesso ou não destes à rede mundial de computadores $(x 2=75.008$ e $\mathrm{p}=0.000)$.
}

Sobre o tempo que passou: a imersão na paisagem cibernética e o surgimento de novas temporalidades... 
e de vídeo. Algo também observado no que tange ao uso de servidores de e-mail e compartilhadores de arquivos em formato digital. Ilustrativo disso é o surgimento, a partir de meados de 2002, de instruções normativas e políticas institucionais que passam a regulamentar a utilização de mensageiros instantâneos (MSN, ICQ, GTALK, etc.) e compartilhadores de conteúdo digital baseados nas redes P2P e, mais recentemente, na distribuição via torrent através do bloqueio de portas utilizadas por esses serviços na RNP, assim como, observou-se também nos anos seguintes, uma proliferação de arquivos em formato digital que podem ser tocados nos mais diversos players de música e vídeo, entre eles, os conhecidos mp4's e Ipod's .

Disto depreende-se uma nova forma de relacionar-se com o tempo e o espaço na medida em que, ao centralizar em si diversas mídias e suportes, o computador permite uma compressão da relação espaço-tempo e uma sobreposição de tempos que dantes eram separados. Pode-se ao mesmo tempo que se ouve música e lê o fórum de discussão da aula que se teve a tarde, estar a ler e-mails ou acompanhar as notícias de seu time preferido. Da copresença não-visível do rádio e do outro visível mas nem sempre co-presente da televisão, emerge um outro digital. Um avatar, uma extensão de nosso eu que ganha vida e morte no mundo de GIBSON.

Já no que se refere a capilaridade e o acesso a tecnologias digitais por parte dos licenciados em EAD temos que, a partir de alguns estudos realizados, assim como da nossa própria experiência no curso de Pedagogia a Distância da UFRGS, é possível afirmar frente às pesquisas como as de WAIZELFISZ (2007) que o Brasil ainda se encontra em um processo de inclusão digital na medida em que existem muitos que possuem acesso as tecnologias da informação e comunicação em seus espaços escolares, enquanto outros, e estes ainda são a maioria, ainda não o possuem. Contudo, apesar destas limitações também fazerem parte da realidade dos licenciados em EAD, como aqueles que cursam o curso de Pedagogia a Distância da UFRGS hoje, uma vez que, muitos ainda precisam dirigir-se a um pólo para ter acesso às tecnologias por diversos fatores de desigualdades digitais, é preciso que consideremos isto como um ponto de grande importância no momento do planejamento pedagógico da disciplina, do desenvolvimento de aplicações específicas, de se pensar o trabalho dos tutores e as exigências de uso do suporte informático, etc. como já colocamos anteriormente. 
Neste sentido, é preciso que consideremos essas especificidades no momento em que pensemos em termos de arquiteturas pedagógicas e/ou desenhos instrucionais voltados para esse público específico de modo que, estas, permitam tanto a alunos como professores, subsidiarem sua formação para além dos espaços-tempos convencionais uma vez que, como apontam diversos trabalhos e/ou coletas de dados realizadas junto as alunas do curso de Pedagogia a Distância da UFRGS, há diversos perfis de professores que estão sendo formados

em serviço. É preciso portanto que consideremos tais arquiteturas ou desenhos instrucionais, também, como intermediadores e produtores de saberes docentes, como já escrevemos em outro lugar (MEIRELLES ET AL, 2009). E com isto, torna-se importante que pensemos tanto a interação mútua que estes realizam (PRIMO, 1998) entre eles quanto no caráter dialógico desta interação (FREIRE, 1987), uma vez que, por estarem imersos em sistemas de ensino de natureza diferenciados, ora, como docentes da educação presencial, ora, como discentes da educação a distância, faz-se necessária a construção de uma arquitetura diferenciada que busque dar conta deste tempo espiralado, sobreposto, permitindo ações pedagógicas tanto em tempo síncrono quanto assíncrono, ora de orientação, ora voltada a troca de experiências.

\section{Vivendo na paisagem cibernética: novos sujeitos e novas formas de perceber o mundo}

Se aceitarmos de início que cada escolha on-line pode estar relacionada tanto as possibilidades de programação do ambiente quanto as possibilidades de compreensão da natureza do orientando, neste caso, a natureza humana do discente, é factível pensar sobre a estrutura desta narrativa como também pedagógica. Ou seja, que no momento em que falamos deste "eu cibernético" não estamos, de forma alguma, negando o "eu real" deste sujeito, mas sim, considerando-o como parte constituinte da paisagem cibernética a partir daquilo que CSORDAS (2007) nomina como corpo socializado na paisagem. Contudo, educar é um ato político - e assim sendo é dotado de poder se pensado em termos de relações entre pessoas com capitais culturais e/ou parcelas de poder diferenciadas como enfocam em suas análises autores como BOURDIEU (2007) e FOUCAULT (2002, 1996), entre outros.

Mas Humberto Gessinger já nos lembrava no final dos anos de 1980 de que "toda forma de poder é uma forma de morrer por nada". Algo semelhante ao que lemos em muitos manifestos de ciberpunks que nos cutucavam com seus slogans que, já em 1990, nos 
lembravam que por "trás de toda arquitetura informacional se esconde uma estrutura de poder”. Na literatura acadêmica também são muitos aqueles que nos lembram que é muito mais fácil reproduzir-se estruturas existentes do que produzir-se novas possibilidades a partir daquilo que já existe (BOURDIEU, 1982). No caso da Educação a Distância, isso não é diferente e acaba-se por se reproduzir em diferentes arquiteturas e/ou desenhos instrucionais que nos são apresentados dia após dia, as mesmas propostas pedagógicas de cunho meramente procedimental, processualista e/ou bancário que, na maioria das vezes, reproduzem modelos e perspectivas de ensino existentes nas modalidades convencionais de ensino.

Todavia, não podemos aqui, apenas colocar a cruz sobre os ombros dos professores que atuam e trabalham nesta modalidade de ensino, nem, tão somente nas linhas de programação escritas pelos desenvolvedores que transformam bits e bytes em paisagens cibernéticas cada vez mais elaboradas e dinâmicas, mas que, em grande parte, partem de pressupostos pedagógicos que já se mostraram ineficazes na modalidade presencial, pois, estes, estão, em sua maioria, presos a concepções pedagógicas impostas de cima para baixo por gestores públicos e agências de fomento que normatizam aquilo que é considerado como sendo eficaz e passível de resultados plausíveis e, portanto, financiáveis por parte do Estado. Subverter esta estrutura fortemente hierárquica não é tarefa fácil e são muitos os desafios que se impõem aqueles que possuem tal intento. E, com certeza, o primeiro deles é o de pensar essa nova relação entre o espaço e o tempo.

\section{Pensando o espaço e o tempo em tempos de cibercultura}

Se o tempo-máquina difere daquele que é percebido pelo sujeito e assume um caráter subjetivo quando percebido pela ótica daquele que consome esse tempo, que vive os segundos de aguardo de uma resposta que muitas vezes parecem horas, ou as noites que mal fecha os olhos e acorda depois de horas com a sensação que poucos minutos passaram, tem-se que, em si, sua relatividade depende da intensidade da experiência e quão esta experiência é capaz de apresentar-se ao sujeito como um fato social total (MAUSS, 2003). Neste sentido, pensar o tempo enquanto um fato social total implica em compreender a lugar que determinadas atividades quotidianas, sejam elas rituais ou não, ocupam no quotidiano das pessoas que estão sob seu jugo. 
Em nossa sociedade contemporânea é exemplar o espaço que ocupam algumas datas comemorativas, tais como o Ano Novo, o Natal, a Páscoa, o Dia dos Namorados, o Carnaval, etc., os quais, em diferentes lugares do Brasil e do mundo assumem diferentes graus de totalização. Isso, algo que também podemos observar a partir de meados dos anos de 1990, em nosso quotidiano, quando o uso de computadores pessoais, laptops e celulares impôs um novo estilo de vida a um grande número de pessoas. Vejamos.

Na noite de 31 de dezembro para 1 de janeiro, em quase todos os países do mundo se comemora a passagem do ano e os desejos de "Happy New Year" invadem caixas de e-mails e correspondência, lojas, empresas, escolas, hospitais, casas, etc. E, enfim, apesar de em alguns países como a China e o Japão, assim como os países islâmicos, comemorarem em outras datas, essa passagem de ano, de encerramento de um ciclo, é um marcador praticamente universal fazendo-se presente nas mais diversas comemorações existentes no interior de culturas diversas espalhadas pelo globo ${ }^{7}$. Já o $\mathrm{Natal}^{8}$, festa exclusiva do calendário cristão, diferentemente do ano novo, vincula-se ao nascimento do Messias, de Jesus de Nazaré, sendo no Cristianismo, o centro dos feriados de fim de ano, de modo que, na noite do dia $24 / 12^{9}$, na

\footnotetext{
${ }^{7} \mathrm{Na}$ Itália, o ano novo é a mais pagã das festas e é recebido com fogos de artifícios, acredita-se também que, aqueles que dormem na virada do ano dormirão todo o ano e na noite de São Silvestre, santo cuja festa coincide com o último dia do ano. O costume de comer lentilha na virada do ano no sul do Brasil, vêm daí, uma vez que, para os italianos dois pratos são considerados essenciais nesse dia: o pé de porco e as lentilhas. Estados Unidos: Nos Estados Unidos a passagem de ano mais marcante é a de Nova Iorque onde, na Time Square, o povo se encontra para beber, dançar, etc. enquanto durante a contagem regressiva para o novo ano, uma grande maçã vai descendo no meio da praça e explode exatamente à meia-noite, jogando balas e bombons para todos os lados. Na França o principal ponto é a avenida Champs-Elysées onde, em Paris, próximo ao Arco do Triunfo, os franceses se reúnem, cada um com uma garrafa de champanhe para assistirem a queima de fogos. No Brasil, principalmente no Rio de Janeiro, cerca de um milhão de pessoas se reúnem na praia de Copacabana para assistir a queima de fogos como acontece em diversos lugares do país. É também costume neste dia, vestir-se de branco, pular sete ondas e jogar flores a Iemanjá. E, no outro lado do mundo, entre os os dias 15 de janeiro e 15 de fevereiro comemora-se a entrada do ano chinês, período que é habitual limparem as casas e fazerem muita comida, há também fogos de artifício e as ruas ficam cobertas de pequenos pedaços de papel vermelho.
}

${ }^{8}$ Comemorado no dia 25 de dezembro em quase todo mundo cristão, a exceção dos países eslavos e ortodoxos onde, este, é comemorado no dia 7 de janeiro devido ao fato de estes países basearem-se no calendário juliano. Como festa religiosa, o Natal é comemorado no dia 25 de dezembro desde o século IV no ocidente (Igreja Católica Apostólica Romana) e desde o século V no Oriente (Igrejas Ortodoxas e Eslavas).

9 Neste sentido, devemos lembrar ainda que, a data de comemoração do Natal não é conhecida como o aniversário real de Jesus, mas que, foi escolhida pela Igreja para corresponder à algumas comemorações pagãs já existentes entre os herdeiros da cultura latina tais como as saturnálias romanas, ou ainda, entre aqueles de herança anglo-saxã e celta, com as comemorações do solstício de inverno (NEWTON, 1733).

Sobre o tempo que passou: a imersão na paisagem cibernética e o surgimento de novas temporalidades... 
noite de Natal, inicia-se um ciclo que dura doze dias, chamado Ciclo de $\mathrm{Nata}^{10}$, o qual encerra-se no dia 6 de janeiro, ou Dia dos Reis.

Outra data, também considerada de grande importância no calendário cristão é a Páscoa ${ }^{11}$, onde, os cristãos celebram a Ressurreição de Jesus Cristo depois da sua morte por crucificação na Sexta-feira Santa, a qual teria ocorrido por volta do ano 30 D.C. segundo alguns registros, ou 33 D.C., segundo outros. Contudo, o termo Páscoa também pode se referir ao ano canônico que dura cerca de dois meses desde essa data até o Pentecostes, ou ainda, ao período do Pesach judaico, data em que os judeus comemoram a libertação e a fuga de seu povo escravizado do Egito. Já o dia de San Valentin, comemorado no dia 14 de fevereiro, como é conhecido na maioria dos países anglo-saxões, e, também, em outros países onde foi implantado ao longo do século XX é o dia em que namorados e amigos expressam seu amor e carinho mutuamente ${ }^{12}$. E ainda, temos o Carnaval ${ }^{13}$ data que assume no Brasil um caráter bem mais totalizante que em outros países, mas que, mesmo aqui, assume caráter

\footnotetext{
${ }^{10}$ Ou ainda Época do Natal se traduzido diretamente do inglês (Christmastide) é dos períodos do ano litúrgico considerado de grande importância na maioria das igrejas cristãs. Com pequenas variações locais compreende o período que vai da noite de Natal (24/12) até do dia anterior ao dia anterior ao Dia de Reis (5/1). Este período também é conhecido como os doze dias de natal, quando, vários festivais tradicionais são realizados em diversos lugares do mundo.
}

${ }^{11}$ Dentre as tradições pagãs é comum a prática de pintar-se ovos cozidos, costume, este ainda muito comum em diversos países, embora em outros, como o Brasil, esses ovos tenham sido substituídos por ovos de chocolate. No entanto, esse costume de pintar os ovos não é citado na Bíblia, mas sim, faz alusão a antigos rituais pagãos dedicados a Ostera, a deusa da fertilidade e do renascimento na mitologia anglo-saxã, nórdica e germânica. Outra curiosidade acerca da Páscoa reside no fato de como o "Coelho" e a frase "Coelhinho da Páscoa que trazes para mim?" destacam-se como símbolos desta hoje. No que se refere ao primeiro temos que, segundo as tradições supracitadas que, na primavera, pintavam e decoravam lebres e ovos com runas que eram os símbolos da fertilidade e renovação associados a Ostera, mas que, quando trazido para dentro da tradição cristã foi substituído pelo coleho. Já no que se refere a segunda temos que suas sacerdotisas, eram tidas como capazes de prever o futuro observando as entranhas de uma lebre sacrificada - e, é claro que a versão comercial: "Coelhinho da páscoa, que trazes pra mim?" é bem mais interessante do que a rima original: "Lebre de Eostre, o que suas entranhas trazem de sorte para mim?".

12 A exceção de alguns países como o Brasil que o comemoram no dia 12 de junho. Neste sentido, importa lembrar que esta data possui assim como as outras datas supracitadas até agora dois referentes. Um religioso que até o Concílio de Vaticano II celebrava, neste dia, pelo menos 3 dos 11 dias dedicados a San Valentin, são eles: 1) Valentin de Roma, sacerdote romano martirizado por volta do ano de 269 D.C.; 2) Valentin de Terni, que no ano de 197 D.C. foi nomeado bispo de Terni; e, 3) um terceiro Valentin, este mencionado na Enciclopédia Católica e seu martírio localizado na África com muitos de seus companheiros. E outro pagão, muito mais controverso que relaciona esse dia as comemorações do mês de Gamelion, este dedicado ao casamento de Zeus e Hera, ou ainda, as Lupercálias, rito pagão realizado no dia 15 de fevereiro e dedicadas ao deus da fertilidade, o fauno Luperco.

13 O Carnaval é um período de festas regidas pelo ano lunar no Cristianismo que surgiu a partir da implantação, no século XI, da Semana Santa pela Igreja Católica. Esta, antecedida por quarenta dias de jejum e privações da carne, a Quaresma. E deste modo, esse longo período de privações acabou por incentivar diversas festividades nos dias que antecediam a Quarta-feira de Cinzas. A palavra "carnaval" está, portanto, relacionada com a idéia de "afastamento" dos prazeres da carne. E assim, tornou-se comum que, a partir da Idade Média, nos três dias que antecedem a Quaresma houvesse uma grande concentração de festas populares. Mas o Carnaval moderno como conhecemos, repleto de fantasias e desfiles é um produto da sociedade vitoriana do século XIX.

Sobre o tempo que passou: a imersão na paisagem cibernética e o surgimento de novas temporalidades... 
diverso e envolve em menor ou maior grau diferentes regiões e cidades do país. Todavia, diferentemente das anteriores ele não é um festejo religioso, mas sim, marcado a partir de um referente religioso, o período da Quaresma.

Neste sentido, o que quis mostrar com isso, e aqui usei-me de algumas datas comemorativas comuns a cultura ocidental é que, dependendo do "marcador" ou "referente" que utilizemos e da cultura a que nos referimos, este, terá maior ou menor incidência e significado de modo que, possuirá maior ou menor alcance dependendo dos condicionantes históricos e do lugar que, por exemplo, o cristianismo, ocupa em sua cosmogonia. Da mesma forma, se seguirmos essa linha de pensamento e pensarmos o indivíduo como socializado na e pela paisagem (CSORDAS, 2007) veremos que ao mesmo tempo em que este produz a cultura é, também, produto dela. E, desta forma é correto afirmar que, enquanto comunidade de sentido (BACZKO, 1985), todos aqueles que convivem e se utilizam dessas diferentes tecnologias, de alguma forma, seja em menor ou maior grau, estão a ela "conectados" e sofrem seus efeitos, de estar "In-Line", "On-Line" ou "Off-Line".

Mas, em tempos de cibercultura, estar off-line é praticamente impossível. Instant Messengers e aplicativos de e-mail pululam em todo tipo de celular produzido nos últimos dois anos. É possível ainda postar em seu Facebook ou Orkut via SMS, assim como, receber desses sites as atualizações via mensagem de texto. Compras realizadas com cartão de crédito e/ou movimentos bancários podem ser monitorados pela tela do celular através de mensagens de texto enviadas pela sua operadora de cartão ou banco a cada nova movimentação, assim como, através de seu celular, também, é possível acessar a internet e fazer movimentações em sua conta sem, ao menos, ter acesso a um PC. E, de fato, com a atual base de celulares que, hoje, no Brasil, supera o número de telefones fixos ${ }^{14}$, é praticamente impossível não estar "InLine", a não ser que "você esteja fora da área de cobertura" ou com "o aparelho temporariamente desligado".

\footnotetext{
${ }^{14}$ Segundo dados divulgados pela Anatel e publicados no Caderno de Economia, do jornal "O Estado de São Paulo" (disponível em: http://economia.estadao.com.br/noticias/not 5884.htm) temos que o número de celulares ativos no Brasil chegou nesse mês de fevereiro a cada dos 175,6 milhões de aparelhos. Segundo ainda a referida reportagem, temos que somente no mês de janeiro de 2010 foram vendidos 1,64 milhão de novas linhas o que, em relação ao mês de dezembro de 2009 , representou um crescimento de $0,94 \%$. E assim sendo, segundo os números divulgados, tem-se que, a cada grupo de 100 pessoas, 91 possuem no mínimo um aparelho celular. No que se refere ao número de telefones fixos temos que, segundo a Agência especializada Teleco (disponível em: http://www.teleco.com.br/estatis.asp), esse número no ano de 2009, chegou a casa dos 41,7 milhões de linhas, cerca de um quarto, do número de linhas móveis.
}

Sobre o tempo que passou: a imersão na paisagem cibernética e o surgimento de novas temporalidades... 
Mas, se por um lado, a estratégia do "In-Line" é compulsória e não nos dá outra opção que não seja uma saída radical, de não ter um aparelho celular e/ou de optar por estar com ele desligado, por outro, escolher entre estar "On-Line" e "Off-Line" é uma questão de escolha, de recursos e de adesão à novas tecnologias e dispositivos que, a cada quatro meses, são despejados no mercado através de campanhas massivas nos mass-media, mas principalmente entre o público jovem. Essa nova geração, também chamada de Geração $\mathrm{X}^{15}$, as quais se sucederam as Gerações Y e Z. Mas, são esse dois últimos segmentos em específico que aqui nos interessam. Os primeiros ligados a chamada Geração Y se refere aqueles jovens nascidos entre o início dos anos de 1970 e meados de 1990 que, em sua maioria, presenciaram grandes mudanças no seu quotidiano com o surgimento dos primeiros computadores pessoais, dos CDs, dos DVDs, dos celulares, da Internet, etc. Os segundos nascidos entre o início dos anos de 1990 e meados de 2000, pertencentes ao que se convencionou chamar na Sociologia de Geração Z, em sua maioria essa não concebem o mundo sem a existência de computadores, chats e telefones celulares. De uma maneira geral, estes últimos, são menos deslumbrados com a tecnologia do que os da Geração Y e sentem-se à vontade fazendo mil coisas ao mesmo tempo, tais como: ver televisão, ouvir rádio, falar ao telefone, ouvir música e acessar a internet, entre outras. Pensam rápido e de forma complexa, além de, possuírem pouco apego as fronteiras geográficas, de modo que, se colocam muitas vezes como cidadãos do mundo.

Os da Geração X têm hoje entre 20 e 40 anos e estão entrando no mercado de trabalho, trabalhando em empresas, pesquisando em universidades e usando o que de melhor a tecnologia têm a lhe oferecer: comodidade, rapidez, conforto. O preço é caro, o horário de trabalho estende-se através de ambientes corporativos e da necessidade de se estar sempre "In-Line" com seu "BlackBerry" ou "IPhone". Seus filhos, estes pertencentes a Geração Z, têm hoje entre 5 e 20 anos de idade e usar a internet, ouvir e baixar música digital é para eles uma realidade de modo que, muitos nem chegaram a ver ou conhecer um toca-discos ou uma máquina de escrever, muito menos, usar o serviço de correio para enviar uma carta a um amigo, uma vez que, estes, nasceram já usando os serviços de correio eletrônico e disco virtual do Yahoo, ao mesmo tempo em que, faziam suas pesquisas usando o Altavista e o

\footnotetext{
${ }^{15}$ É um termo usado para na demografia, nas ciências sociais e no marketing para descrever uma geração de pessoas que nasceram entre 1965 e 1981. De uma maneira geral, também são chamados de a "geração perdida" pois cresceram num novo mundo sem utopias tendo que se conformar com um padrão de vida mais realista e global. Em geral eram filhos de pais separados, ou viviam em casas onde tanto o pai como a mãe trabalhavam fora, assistiram a decadência de antigos padrões sociais em nome de outros mais eficazes.
}

Sobre o tempo que passou: a imersão na paisagem cibernética e o surgimento de novas temporalidades... 
Cadê. Isso tudo, a menos de 10 ou 12 anos atrás, quando o Google era apenas uma idéia na cabeça de dois jovens que trabalhavam numa garagem no Vale do Silício.

Enfim, o tempo passa, as coisas mudam e adaptar-se a elas é uma questão de sobrevivência. Neste sentido, é fato que a EAD chegou para ficar e que, queiramos ou não, em breve, estaremos em frente a um PC em videoconferência com centenas de alunos ao redor do mundo. Bancos, lojas, universidades já se virtualizaram... e você?

\section{Considerações Finais}

Assim, temos a partir do exposto que, cada vez mais, a partir de um mesmo dispositivo, uma pluralidade de serviços podem ser acessados alterando significativamente o modo de vida e a forma como as pessoas, mas principalmente os jovens das gerações $\mathrm{Y}$ e $\mathrm{Z}$, se relacionam com o tempo e com o espaço na medida em que, um ônibus, um avião, o bar da faculdade ou aquele perto de sua casa passa a ser, também, seu escritório, a partir do qual este jovem acessa seus e-mails através de uma conexão wi-fi ou $3 \mathrm{G}$, interage em diferentes redes sociais, troca mensagens de texto, assiste vídeos no youtube, coloca fotos no ar, etc. O mesmo acontece nas salas de aula do ensino médio, onde, ao mesmo tempo em que assistem as aulas, estes, estão acessando a internet, ouvindo música, postando no Orkut e/ou no Facebook, trocando mensagens de texto, etc. - tudo isso, a partir de seu aparelho celular.

Deste modo, o celular, assim como o computador, hoje, assume um lugar importante no quotidiano do homem moderno, mas principalmente no interior do universo jovem, ao ponto de, alterar, significativamente, a relação destes com o tempo e com o espaço pois, este, pode, na atualidade, a partir de um mesmo dispositivo, fazer-se coisas que antes tinham que ser feitas em separado e a partir de diferentes dispositivos de hardware. O aparelho de som é "aposentado" ou "conectado" ao "computador" ou "Ipod" para que possa tocar seu acervo de cerca de quatro mil músicas em mp3. O DVD e a TV, também, conectados ao PC exibem os arquivos de vídeo baixados da rede, inclusive, aqueles filmes que ainda nem chegaram aos cinemas comerciais daqui. Ah, tocou o telefone no PC? Sem problemas, o Skype automaticamente pausa os players de música e vídeo para que você possa falar tranquilamente, mas, enquanto isso, vamos lendo umas notícias no ZH Digital e postando alguma coisa no fórum da disciplina de Sociologia Clássica lá no Moodle. 
Na educação a distância, ou entre aqueles da educação presencial que usam de alguma forma o computador no seu quotidiano isso não é muito diferente e já se fala inclusive em plataformas de ensino voltadas para dispositivos móveis. Outrossim, diante do exposto temos que, assim como os diferentes marcadores culturais e religiosos que citamos anteriormente, o computador e o celular são, em nossos dias, dois artefatos tecnológicos que impõem ao homem moderno um novo modo de vida, onde, este, é obrigado a escolher entre estar "OnLine” ou "Off-Line". O grau de imersão dele na paisagem cibernética dependerá somente de sua escolha e do quanto ele estará “On-Line”, como é o caso, por exemplo, de muitos dos trabalhos que elegeram como temática de seu artigo de encerramento desta especialização as noções de alfabetização tecnológica e de letramento digital. 


\section{Referências bibliográficas}

BACZKO, Bronislaw. Imaginação social. In: ROMANO, Ruggiero (org.). Enciclopédia Einaudi. Lisboa: Imprensa Nacional; Casa da Moeda, 1985. v. 5.

BAUMER, Bettina. Apêndice: A percepção empírica do tempo. In: RICOUER, Paul (Org.) As Culturas e o tempo: estudos reunidos pela Unesco. Petrópolis: Vozes; São Paulo: Editora da USP, 1975, p. 95-101.

BIANCHETTI, Lucídio. Da Chave de Fenda ao Laptop - Tecnologia Digital e Novas Qualificações: Desafios à Educação. Petrópolis-Florianópolis: Vozes, 2001.

BOURDIEU, Pierre. O poder simbólico. Rio de Janeiro: Bertrand Brasil, 2007.

BOURDIEU, Pierre. A reprodução: elementos para uma teoria do sistema de ensino. Rio de Janeiro: Francisco Alves Editor, 1982.

CASTELLS, Manuel. A Sociedade em Rede - A Era da Informação: economia, sociedade e cultura. Volume 1. São Paulo: Paz e Terra, 1999.

CASTELLS, Manuel. A Galáxia Internet: Reflexões Sobre a Internet, os Negócios e a Sociedade. Rio de Janeiro: Jorge Zahar Editores, 2003.

CSORDAS, Thomas. Corpo|Significado|Cura. Porto Alegre: Editora da UFRGS, 2007.

CUNEGATTO, Thaís. Etnografia da Rua da Praia: um estudo antropológico sobre cotidiano, memória e formas de sociabilidade no centro urbano porto-alegrense. Porto Alegre: UFRGS/ PPGAS, 2009. Dissertação de Mestrado.

DEVOS, Rafael Victorino. A "questão ambiental" sob a ótica da antropologia dos grupos urbanos, nas ilhas do Parque Estadual Delta do Jacuí, Bairro Arquipélago, Porto Alegre, RS. Porto Alegre: UFRGS/PPGAS, 2007. Tese de Doutorado.

ECKERT, Cornélia \& ROCHA, Ana Luiza Carvalho da. "Imagens do tempo nos meandros da memória: por uma etnografia da duração". IN: Revista Iluminuras, V.1, n.1. Porto Alegre: UFRGS/PPGAS, 2000.

FREIRE, Paulo. Pedagogia do Oprimido. São Paulo: Paz e Terra, 1987.

FOUCAULT, Michel. Microfísica do poder. Rio de Janeiro: Graal, 2002.

FOUCAULT, Michel. Vigiar e punir: o nascimento da prisão. Petrópolis: Vozes, 1996.

GIBSON, William. Neuromancer. São Paulo: Aleph, 1984. 
GOUREVITCH, A. Y.. O Tempo como problema de história cultural. In: RICOUER, Paul (Org.) As Culturas e o tempo: estudos reunidos pela Unesco. Petrópolis: Vozes; São Paulo: Editora da USP, 1975, p. 263-283.

KAGAME, Alexis. A percepção empírica do tempo e a concepção da história no pensamento bantu. In: RICOUER, Paul (Org.) As Culturas e o tempo: estudos reunidos pela Unesco. Petrópolis: Vozes; São Paulo: Editora da USP, 1975, p. 102-135.

KUPER, Adam. Cultura: a visão dos antropólogos. Bauru: EDUSP, 2002.

LARRE, Claude. A percepção empírica do tempo e a concepção da história no pensamento chinês. In: RICOUER, Paul (Org.) As Culturas e o tempo: estudos reunidos pela Unesco. Petrópolis: Vozes; São Paulo: Editora da USP, 1975, p. 41-72.

LATOUR, Bruno. Jamais Fomos Modernos. Rio de Janeiro: Editora 34, 2000.

LEVY, Pierre. As Tecnologias da Inteligência: o futuro do pensamento na era da informática. Rio de Janeiro: Ed.34, 1997.

MAUSS, Marcel. Sociologia e antropologia. São Paulo: Cosac Naify, 2003.

MEIRELLES, Mauro. A Inserção Brasileira na Era da Informação: Excluídos Digitais ou Tecnológicos? IN: Informática na Educação: teoria \& prática, Porto Alegre, v. 6, n. 1, p. 69-83, jan./jun. 2003.

MEIRELLES, Mauro. As redes que se tecem nas escolas públicas de ensino médio de Porto Alegre: o uso das tecnologias digitais e a construção de indicadores de fluência digital a partir de uma abordagem sociotécnica. Porto Alegre: UFRGS/PPGEDU, 2005. Dissertação de Mestrado.

MEIRELLES, Mauro; BOLL, Cíntia Inês; ANDRADE, Felipe; BARCELOS, Fernanda; FORNARI, Michelle. Diving into cybernetics landscape: hypermidiatic narratives into training of licenciature scholars of EAD. 2009. Mimeo.

MCLUHAN, Herbert Marshall. O meios de comunicação como extensões do homem. São Paulo: Cultrix, 1969.

NEHER, André. Visão do tempo e da história na cultura judaica. In: RICOUER, Paul (Org.) As Culturas e o tempo: estudos reunidos pela Unesco. Petrópolis: Vozes; São Paulo: Editora da USP, 1975, p. 176-196.

PANIKKAR, Raimundo. Tempo e História na tradição da Índia. In: RICOUER, Paul (Org.) As Culturas e o tempo: estudos reunidos pela Unesco. Petrópolis: Vozes; São Paulo: Editora da USP, 1975, p. 73-94. 
PATTARO, Germano. A concepção cristã do tempo. In: RICOUER, Paul (Org.) As Culturas e o tempo: estudos reunidos pela Unesco. Petrópolis: Vozes; São Paulo: Editora da USP, 1975, p. 197-228.

PRIMO, Alex. Interação Mútua e Interação Reativa: uma proposta de estudo. XXI Congresso da Intercon - Recife PE, set. 1998.

RICOEUR, Paul. “Tempo e narrativa. A tríplice mimese”. In: RICOEUR, Paul. Tempo e narrativa. Tomo I, Campinas, Papirus, 1994, p. 85-131.

RICOEUR, Paul. "Introdução". In: RICOUER, Paul (Org.) As Culturas e o tempo: estudos reunidos pela Unesco. Petrópolis: Vozes; São Paulo: Editora da USP, 1975, p. 15-40.

SILVEIRA, Sergio Amadeu da. Exclusão Digital - A Miséria na Era da Informação. São Paulo: SP: Fundação Perseu Abramo, 2001.

SORJ, Bernardo. BRASIL@,POVO.COM: A Luta Contra a Desigualdade na Sociedade da Informação. Rio de Janeiro: Jorge Zahar Editores/UNESCO, 2003.

WAISELFISZ, Júlio Jacobo. Mapa das Desigualdades Digitais do Brasil. RITLA. Brasília: 2007.

\section{Documentos Eletrônicos}

NATIONAL RESEARCH COUNCIL (U.S.) COMMITEE ON INFORMATION TECHNOLOGY LITERACY. Being Fluent with information technology. Washington, DC: National Academy Press, 1999. Disponível em: < http://books.nap.edu/books/030906399X/

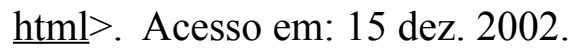

NEWTON, Isaac. Of the Times of the Birth and Passion of Christ. IN: Observations upon the Prophecies of Daniel, and the Apocalypse of St. John. Londres, 1733. Disponível em: http:// www.gutenberg.org/files/16878/16878-h/16878-h.htm. Acesso em: 07 jan. 2009.

TIRADO, Francisco Javier, GÀLVEZ, Anna. Comunidades virtuales, cyborgs y redes sociotécnicas: nuevas formas para la interación social. IN: Digit•HvM - Revista Digital d'Humanitats, 2002, n. 4. Disponível em: http://www.uoc.edu/humfil/articles/esp/ tiradogalvez0302.html. Acesso em 16 fev. 2004. 